\title{
AN EVALUATION OF THE COURSEBOOK "LIFE ELEMENTARY" USED FOR STUDENTS AT UNIVERSITY OF INFORMATION AND COMMUNICATION TECHNOLOGY: FROM TEACHERS' PERSPECTIVES
}

\author{
Tran Minh Thanh ${ }^{1 *}$, Nguyen Thuy Linh ${ }^{1}$, Nguyen Thi Bich Ngoc ${ }^{2}$ \\ ${ }^{I} T N U$ - University of Information and Communication Technology \\ ${ }^{2} \mathrm{TNU}$ - School of Foreign Languages
}

\section{ABSTRACT}

In English as a foreign language teaching, coursebook evaluation is an indispensable ongoing task to ensure training quality. In this study, we evaluate the coursebook "Life Elementary" which has been used as the official material for students at TNU-University of Information and Communication Technology (ICTU). The study aims at enhancing the effectiveness of using the coursebook to meet the English requirements for students from related stakeholders. 14 English teachers from TNU-University of Information and Communication Technology took part in a survey. The research results reveal that although there are some weaknesses in terms of the boredom of writing activities, inadequate pronunciation practice, and unfamiliar cultural contents, the coursebook "Life Elementary" essentially is relevant to the training objectives and the university's teaching-learning context. Implications for better use of the coursebook are proposed. This study is a useful source of reference for English teachers who are interested in coursebook evaluation in particular and training institutions with similar contexts.

Keywords: English teaching; evaluation; coursebook evaluation; learning materials; adaptation.

Received: 20/10/2019; Revised: 01/12/2019; Published: 21/02/2020

\section{ĐÁNH GIÁ GIÁO TRÌNH "LIFE ELEMENTARY" DÙNG CHO SINH VIÊN TRƯỜNG ĐẠI HỌC CÔNG NGHÊ THÔNG TIN VÀ TRUYỀN THÔNG - ĐẠI HỌC THÁI NGUYÊN TỪ GÓC NHÌN CỦA GIÁO VIÊN}

\author{
Trần Minh Thành ${ }^{*}$, Nguyễn Thùy Linh ${ }^{1}$, Nguyễn Thị Bích $\operatorname{Ngọc}^{2}$ \\ ${ }^{1}$ Trưòng Đại hoc Công nghệ Thông tin và Truyền thông - ĐH Thái Nguyên \\ ${ }^{2}$ Khoa Ngoại ngũu - ĐH Thái Nguyên
}

\section{TÓM TẮT}

Trong việc giảng dạy tiếng Anh như một ngoại ngữ, việc đánh giá giáo trình là một công việc liên tục không thể thiếu để đảm bảo chất lượng đào tạo. Trong nghiên cứu này, chúng tôi đánh giá giáo trình "Life Elementary" được sử dụng làm tài liệu học tập chính thức cho sinh viên tại Trường Đại học Công nghệ Thông tin và Truyền thông - Đại học Thái Nguyên. Mục đích của nghiên cứu là nhằm nâng cao hiệu quả của việc sử dụng giáo trình và qua đó đáp ứng được các yêu cầu về trình độ tiếng Anh đối với sinh viên đến từ cá nhân, tổ chức liên quan. 14 giáo viên tiếng Anh từ Trường Đại học Công nghệ Thông tin và Truyền thông đã tham gia trả lời khảo sát. Kết quả nghiên cứu cho thấy rằng mặc dù có một số điểm yếu như hoạt động viết còn nhàm chán, hoạt động thực hành phát âm còn ít và một số nội dung văn hóa còn chưa phù hợp nhưng về cơ bản giáo trình đáp ứng và phù hợp với mục tiêu đào tạo, thực tiễn dạy - học tại trường. Nghiên cứu cũng đưa ra các gợi ý sư phạm cho việc hiệu chỉnh và sử dụng giáo trình hiệu quả hơn. Nghiên cứu này là một nguồn tài liệu tham khảo hữu ích cho các giáo viên tiếng Anh quan tâm đến việc đánh giá giáo trình nói riêng và các đơn vị đào tạo có đặc điểm dạy - học tương tự nhà trường.

Từ khóa: Giảng dạy tiếng Anh; đánh giá; đánh giá giáo trình; học liệu; hiệu chỉnh giáo trình.

Ngày nhận bài: 20/10/2019; Ngày hoàn thiện: 01/12/2019; Ngày đăng: 21/02/2020

* Corresponding author. Email: tmthanh@ictu.edu.vn

DOI: https://doi.org/10.34238/tnu-jst.2020.03.2236 


\section{Introduction}

In foreign language teaching, Mukundan et al. argued the choice of materials could be the determinant of the quality of learning-teaching procedure, and of achieving expected training objectives [1]. While publishers have made hard attempts to provide stakeholders like teachers and students with good commercial coursebooks, there is no one-size-fits-all coursebook totally being able to fit all designed curriculum, teaching and learning contexts. Therefore, the evaluation and adaptation of a coursebook are ongoing must-do tasks to ensure the training quality. In ICTU curriculum, English subject accounts for 12 credits, which are distributed into four courses namely English 1, English 2, English 3 and English 4. The objectives of the first three courses are: By the end of these courses, students are expected (1) to achieve the English language proficiency standard of A2 according to the Common European Framework for Reference (CEFR) [2]; and (2) to have positive attitudes towards English learning. Before 2017, the official coursebooks employed for these courses were "English Unlimited A2" and "English Unlimited B1." However, as reported by Tran Minh Thanh et al., up to $46 \%$ of students get mark D or F for the final exams [3]. Beside the subjective reasons from students, there is mutual consent among teachers that the two coursebooks were not relevant to ICTU context. Therefore, they have made decision to adopt a new coursebook "Life Elementary" published by National Geographic Learning as a replacement. "Life Elementary" is colorfully printed and partially designed based on blended-learning model. The coursebook is used in three courses English 1, English 2 and English 3. As mentioned, the evaluation and adaptation are indispensable during English teaching and learning, but since the adoption of the new coursebook, there is no formal research conducted to evaluate its relevance to training objectives. Moreover, in some daily narratives with teachers and students, the coursebook seems to reveal some limitations to both teaching and learning.
Having inspired by the current situation and expecting to improve English teaching and learning at ICTU, we carried out this study to evaluate the relevance of the coursebook "Life Elementary" to training objectives as well as to find out the strengths and weaknesses for better using it.

\section{Literature review}

According to Tomlinson, a coursebook is a textbook including work on grammar, vocabulary, functions, and the skills of reading, writing, listening and speaking, which provides the core materials for a course [4]. The term "coursebook" is sometimes associated with text materials as it has been specially selected and exploited for teaching purposes by teachers, particularly in the local setting. Therefore, the terms 'textbook', 'coursebook', and 'materials' are frequently used interchangeably.

Coursebook evaluation is essential for the improvement of a language course as it helps to identify particular strengths and weaknesses of the materials in use. After being used for some time, the coursebook need evaluating to see if it has worked well to meet the expectations of stakeholders. Varied concepts of materials evaluation have been formulated. Dudley argued, "Evaluation is a whole process which begins with determining what information to gather and end with bringing about the change in the current activities or influencing future ones" [5]. Tomlinson claimed, "This term refers to attempts to measure the value of materials." [4]. Hutchinson and Waters defined that evaluation is a matching process designed to establish the degree of match between the needs and available solutions. It refers to the attempts to measure the value of materials and is aimed at assessing the fitness [6]. In summary, though researchers have their own viewpoints, they still come to the agreement that materials evaluation is a process of collecting data, giving judgments based on collected data, and the most importantly, it must identify whether the materials is relevant to the training objectives of a curriculum. The results of evaluation normally embrace actions of changes. 
Concerning types of evaluation, Cunningsworth [7] and McGrath [8] divide into three types: pre-use, in-use, and post-use evaluation, of which post-use evaluation refers to an assessment of a textbook's fitness over a period of continual use. According to Tomlinson, evaluation of this kind can be "the most valuable as it can measure the actual effect of the material on the users". Based on the data measured, evaluators can make reliable decisions about the use, adaptation, or replacement of the materials [4]. Being aware of the suitability of post-use evaluation with the outlined research objectives and ICTU context, the authors employed post-use evaluation.

With respect to methods of evaluation, researchers have classified into three primary ones: the impressionistic method, checklist method, and in-depth method. According to Cunningsworth, the impressionistic method is to gain an impression of a book by looking rather than more carefully at representative features or more specific features such as the treatment of particular language elements [7]. McGrath argued, "A checklist is likely to need tailoring to suit a particular context, and this can involve a good deal more than simply deleting checklist items which are in applicable" [8]. The in-depth method consists of a focus on specific features [7], close analysis of one or more extracts [6], or throughout the examination of two units using predetermined questions [8]. However, the indepth method has certain disadvantages. Firstly, samples selected for analysis may not be representative of the book as a whole. Secondly, only a particular section of the material is focused. Moreover, this method takes time and requires expert knowledge.

As novice teacher researchers, the authors decided to use the checklist method for its convenience and ease of use.

\section{Methodology}

\subsection{Research questions}

The study aimed at evaluating the coursebook "Life Elementary" used for ICTU students to find out how well the coursebook matches the training objectives. Its findings help to propose adjustments to enhance the use of the coursebook as well as the learning-teaching quality of English courses at ICTU. The study, therefore, was carried out to address the following research question: Is the coursebook "Life Elementary" relevant to the training objectives?

\subsection{Participants}

The participants of the study were 14 ICTU English teachers aging from 31 years to 49 years old, and having teaching experience from seven to 25 years. One of them is male and the rest are female. They all have taught the first three English courses with the examined coursebook. 13 participants hold master degrees of art in English, and one has a doctor degree in English language.

\subsection{Data collection instrument}

Based on the research scopes and the real teaching situation of the research context, the authors used a questionnaire, which was adapted based on the checklist proposed by Mukundan et al. The adapted checklist was formed by deleting the items for evaluating "Physical and utilitarian attributes" and "Efficient outlay of supplementary materials"; and by adding some words to the items of teaching-learning content surrounding A2 level to make them clear to participants.

\subsection{Data collection procedure and analysis}

The questionnaire was administered to 14 teachers from Department of English to collect their judgments of the coursebook. Then, the obtained data were put into Microsoft Excel for calculating the percentage. Finally, the results were analyzed and compared.

\section{Results and discussions}

\subsection{Teachers' evaluation of general attributes}

Investigating the coursebook and its integrated curriculum is highly necessary because they reflect obviously what the teachers teach and what the students learn. The first part of the survey questionnaire aims to get teachers' evaluation of general attributes of the coursebook. 
Table 1. Teachers' evaluation of general attributes (\%)

\begin{tabular}{|c|c|c|c|c|c|}
\hline Opinions & 4 & 3 & 2 & 1 & $\mathbf{0}$ \\
\hline $\begin{array}{l}\text { A. The book in relation to syllabus and curriculum } \\
\text { 1. It matches to the specifications of the syllabus. } \\
\text { B. Methodology }\end{array}$ & 35.7 & 57.2 & 0 & 7.1 & 0 \\
\hline $\begin{array}{l}\text { 2. The activities can be exploited fully and can embrace the } \\
\text { various methodologies in ELT. }\end{array}$ & 7.1 & 78.7 & 7.1 & 7.1 & 0 \\
\hline $\begin{array}{l}\text { 3. Activities can work well with methodologies in ELT. } \\
\text { C. Suitability to learners }\end{array}$ & 7.1 & 85.7 & 0 & 7.1 & 0 \\
\hline 4. It is compatible to background knowledge and level of students. & 35.7 & 57.2 & 0 & 7.1 & 0 \\
\hline 5. It is compatible to the socio-economic context. & 14.3 & 57.2 & 21.4 & 7.1 & 0 \\
\hline 6. It is culturally accessible to the learners. & 21.4 & 57.2 & 7.1 & 14.3 & 0 \\
\hline 7. It is compatible to the needs of the learners. & 7.1 & 78.7 & 7.1 & 7.1 & 0 \\
\hline 8. It is compatible to the interests of the learners. & 35.7 & 57.2 & 0 & 7.1 & 0 \\
\hline
\end{tabular}

$0=$ Totally disagreed $\quad 1=$ Disagreed $\quad 2=$ Partly agreed $3=$ Agreed $\quad 4=$ Totally agreed

It can be seen in Table 1 that most teachers (over $82 \%$ in total) totally agreed and agreed that general attributes of the coursebook such as "relation to syllabus and curriculum", "methodology" and "suitability to learners" match the training objectives. However, for item 5 "The compatibility to the socioeconomic context," approximately one-third of the teachers $(28.5 \%)$ partly agreed and disagreed. This evaluation is reasonable due to most students come from mountainous provinces and were born in rather low-income families, whereas the coursebook is quite costly. The book is, therefore, not relevant with students' economic conditions.

\subsection{Teachers' evaluation of teaching- learning content}

4.2.1. Teachers' general evaluation of teaching-learning content

The teaching-learning content is considered to be the core component of a coursebook, and it is the most prominent determinant to achieve the training objectives. Table 2 presents teachers' general evaluation of teachinglearning content in the coursebook. The data show that except for cultural sensitivities and fun elements, most teachers, about $72 \%$, agreed that teaching-learning content is relevant. $35.7 \%$ of the teachers reported that the coursebook needs more fun elements, and the figure of teachers partly agreed and disagreed that the cultural sensitivities have been considered in the coursebook is $42.9 \%$ and $7.1 \%$, respectively. The negative judgment about cultural sensitivities is reasonable because language and culture inherently inseparable. Some culture patterns of English language are unfamiliar to Vietnamese students, so it is quite hard for them to recognize these patterns.

Table 2. Teachers' general evaluation of teaching-learning content (\%)

\begin{tabular}{lrrrrr}
\hline \multicolumn{1}{c}{ Opinions } & $\mathbf{4}$ & $\mathbf{3}$ & $\mathbf{2}$ & $\mathbf{1}$ & $\mathbf{0}$ \\
Items & 0 & 78.6 & 14.3 & 7.1 & 0 \\
\hline 1. Most of the tasks in the book are interesting. & 28.6 & 42.9 & 21.4 & 7.1 & 0 \\
2. Tasks move from simple to complex. & 14.3 & 64.3 & 14.3 & 7.1 & 0 \\
3. Task objectives are achievable. & 0 & 50 & 42.9 & 7.1 & 0 \\
4. Cultural sensitivities have been considered. & 35.7 & 35.7 & 28.6 & 0 & 0 \\
5. The language in the textbook is natural and real. & 50 & 28.6 & 7.1 & 14.3 & 0 \\
6. The situations created in the dialogues sound natural and real. & 21.4 & 57.2 & 7.1 & 14.3 & 0 \\
7. The material is up-to-date. & 21.4 & 64.3 & 0 & 14.3 & 0 \\
9. It covers a variety of topics from different fields. & 14.3 & 50 & 21.4 & 14.3 & 0 \\
10. The book contains fun elements. & 1 = Disagreed & 2= Partly agreed & $3=$ Agreed & $4=$ Totally agreed
\end{tabular}

http://jst.tnu.edu.vn; Email: jst@tnu.edu.vn 


\subsubsection{Teachers' evaluation of language skills}

Language learning is presented through all language skills. Table 3 illustrates the teachers' evaluation of four language skills. It is clear that of all four skills, the writing one received the least positive evaluation. Specifically, there were no teachers totally agreeing that writing tasks have achievable goals and take into consideration learner capabilities, or provide enough models for target genres. Up to $50 \%$ of the teachers only partly agreed that writing tasks are interesting. These figures show that writing skill only partly relevant to training objectives in terms of developing learner's positive attitudes to writing and the required writing level. Speaking, listening and reading skills were positively judged by participants. $78.6 \%$ of the teachers totally agreed and agreed that listening tasks are appropriate with defined goals, and have authenticity. Notably, $85.8 \%$ of teachers both agreed and totally agreed that listening instructions are clear. This figure is consistent with the proportion of the teachers' evaluation of appropriateness of listening tasks with set-forth goals and complexity grading. It can be inferred that clear instructions helps students to keep track on their objectives. In short, listening skill well meets the expected training objectives.
Beside the positive evaluation put on the listening skill, a figure of $85.7 \%$ is the number of teachers who totally agreed and agreed that speaking activities are designed for meaningful communication. $78.6 \%$ of participants also reported that the coursebook has balanced speaking activities between individual response, pair work and group work. Another criterion for judging speaking skill is its impact on students' motivation to talk. Statistics in Table 3 shows although the number of teachers had positive evaluation for this criterion was lowest of all three criteria, it remained relatively high, at $71.4 \%$. In summary, speaking skill is relevant to training objectives. The last skill to evaluate is reading one. Generally, this skill was reported to be quite relevant to training objectives. $85.7 \%$ positive responses was given to the interest of reading texts. The grading and suitability in length of reading texts received $78.6 \%$ and $71.5 \%$ of teachers' agreement and total agreement, respectively.

To sum up, except for some weaknesses in the writing skill, the other three skills are quite well relevant to training objectives because they have promoted students' performance to achieve required level, and developed their motivation and positive attitudes towards learning English.

Table 3. Teachers' evaluation of language skills (\%)

\begin{tabular}{|c|c|c|c|c|c|}
\hline Opinions & 4 & 3 & 2 & 1 & $\mathbf{0}$ \\
\hline \multicolumn{6}{|l|}{ Listening } \\
\hline 1. The book has appropriate listening tasks with well-defined goals. & 28.6 & 50 & 21.4 & 0 & 0 \\
\hline 2. Instructions for listening are clear. & 42.9 & 42.9 & 14.2 & 0 & 0 \\
\hline 3. Listening tasks are efficiently graded according to complexity. & 7.1 & 78.7 & 7.1 & 7.1 & 0 \\
\hline 4. Listening tasks are authentic or close to real language situations. & 28.6 & 50 & 21.4 & 0 & 0 \\
\hline \multicolumn{6}{|l|}{ Speaking } \\
\hline 5. Speaking activities are developed to initiate meaningful communication. & 7.1 & 78.6 & 14.3 & 0 & 0 \\
\hline $\begin{array}{l}\text { 6. Speaking activities are balanced between individual response, pair work } \\
\text { and group work. }\end{array}$ & 7.1 & 71.5 & 21.4 & 0 & 0 \\
\hline 7. Speaking activities motivate students to talk. & 7.1 & 64.3 & 28.6 & 0 & 0 \\
\hline \multicolumn{6}{|l|}{ Reading } \\
\hline 8. Reading texts are graded. & 14.3 & 64.3 & 14.3 & 7.1 & 0 \\
\hline 9. The length of reading texts is appropriate. & 42.9 & 28.6 & 28.5 & 0 & 0 \\
\hline 10. Reading texts are interesting. & 14.3 & 71.4 & 14.3 & 0 & 0 \\
\hline \multicolumn{6}{|l|}{ Writing } \\
\hline $\begin{array}{l}\text { 11. Writing tasks have achievable goals and take into consideration learners' } \\
\text { capabilities }\end{array}$ & 0 & 71.4 & 14.3 & 14.3 & 0 \\
\hline 12. Writing models are provided for different genres. & 0 & 78.6 & 14.3 & 0 & 7.1 \\
\hline 13. Writing tasks are interesting. & 0 & 42.9 & 50 & 0 & 7.1 \\
\hline
\end{tabular}


Table 4. Teachers' evaluation of linguistic aspects (\%)

\begin{tabular}{lrrrrr}
\hline \multicolumn{1}{c}{ Opinions } & $\mathbf{4}$ & $\mathbf{3}$ & $\mathbf{2}$ & $\mathbf{1}$ & $\mathbf{0}$ \\
\hline Linguistic aspects & & & & & 0 \\
\hline Vocabulary & 14.3 & 71.5 & 7.1 & 7.1 & 0 \\
1. The vocabulary load is appropriate to A2 level. & 7.1 & 64.3 & 21.5 & 7.1 & 0 \\
2. There is a good distribution of vocabulary load across chapters & & & \\
and the whole book. & 21.4 & 42.9 & 28.6 & 7.1 & 0 \\
3. Words are efficiently repeated and recycled across the book. & 7.1 & 78.6 & 14.3 & 0 & 0 \\
4. Words are contextualized. & & & & & \\
Grammar & 14.3 & 71.4 & 14.3 & 0 & 0 \\
5. The spread of grammar is achievable at A2 level. & 7.1 & 78.6 & 14.3 & 0 & 0 \\
6. The grammar is contextualized. & 0 & 50 & 42.9 & 7.1 & 0 \\
7. Grammar examples are interesting. & 7.1 & 78.6 & 14.3 & 0 & 0 \\
8. Grammar is introduced explicitly. & 14.3 & 57.2 & 28.5 & 0 & 0 \\
9. Grammar is reworked implicitly throughout the book. & & & & & 0 \\
Pronunciation & 7.1 & 57.2 & 35.7 & 0 & 0 \\
10. Pronunciation is easy to learn. & 0 & 35.7 & 50 & 14.3 & 0 \\
11. There are enough pronunciation practices. & 3.7 & & \\
\hline
\end{tabular}

$0=$ Totally disagreed $\quad 1=$ Disagreed $\quad 2$ = Partly agreed $3=$ Agreed $\quad 4=$ Totally agreed

\subsubsection{Teachers' evaluation of linguistic aspects}

There are three things involved in knowing a language - vocabulary, grammar and pronunciation. When evaluating a coursebook, it would be inadequate if the evaluator did not take into consideration these aspects. Table 4 shows teachers' evaluation of these linguistic respects. Overall, virtually criteria of vocabulary and grammar were positively evaluated, whereas one criterion of pronunciation received quite negative responses. Specifically, about $85.8 \%$ of teachers supposed the vocabulary load is appropriate to A2 level, and a similar figure responded that words are contextualized. The distribution, repetition, and sequencing of vocabulary were reported to be satisfactory and effective by most teachers, at over $71 \%$.

With regard to grammar, statistics obviously show that teachers made a positive evaluation. Specifically, at least $71.4 \%$ of the teachers scrutinized grammatical items to be well achievable, contextualized, explicitly introduced and implicitly reworked. However, only seven teachers $(50 \%)$ said that grammar examples are interesting, whereas the rest either partly agreed or disagreed with this grammar criterion. English pronunciation is incredibly important if someone wants to be understood and avoid miscommunications.
Table 4 shows that pronunciation content is easy for students to learn, which was responded by $64.3 \%$ of teachers. However, the results revealed that the coursebook has a lack of pronunciation practices when only $35.7 \%$ of teachers agreed pronunciation practices are enough. $50 \%$ and $14.3 \%$ of teachers partly agreed and disagreed with the adequacy of pronunciation practices, respectively. In learning a foreign language, it normally takes time to have a good or at least comprehensible pronunciation. Linguists often have consent that good pronunciation requires a great deal of drills and efforts due to some negative transfers from the mother tongue to second or foreign language. Therefore, it is necessary to provide students with an adequate number of practices.

\subsubsection{Teachers' evaluation of exercises}

The last criterion of a coursebook should be evaluated is exercises. It is argued that the appropriate arrangements of exercises with clear instructions can help students to learn and reinforce easily. Soori và Jamshidi argues adequate exercises designed suitably with students' ability can bring about effectiveness for learning process [9]. "Life Elementary" is partially designed based on blended-learning model. Besides offline materials, there are online resources. In the English syllabus of 
three mentioned English courses, students are required to do both printed and online exercises. As it is shown in Table 5, exercises seem to be a positive development in teaching-learning model for ICTU context as the percentage of teachers, at $71.5 \%$, totally agreed and agreed with the its relevance to students. The other two criteria for evaluating exercises - instructions and adequacy - also received positive agreements, at $92.9 \%$ and $78.4 \%$, respectively. These teachers' positive evaluations show the relevance of exercises to training objectives.

Table 5. Teachers' evaluation of exercises (\%)

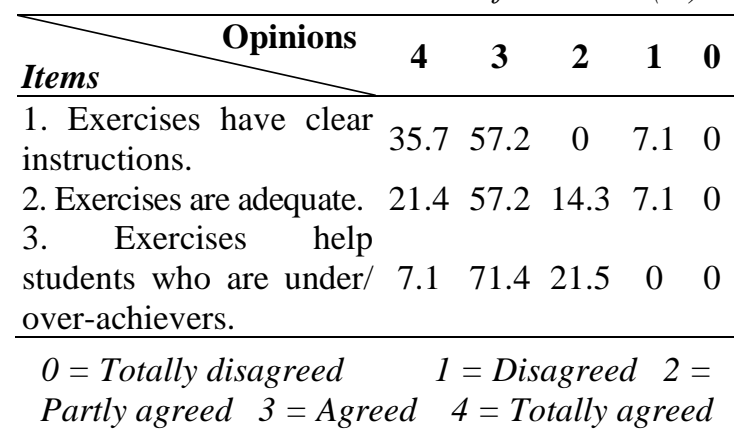

\section{Implications for coursebook use}

Based on the synthesis, analysis and reasoning of results, the authors give the following implications for better employing the coursebook:

\subsection{Implications for writing activities}

As indicated in the findings, writing skill has a lack of genres and is not suitable with students' capabilities. Its tasks also are not interesting. Therefore, teachers should spend some time exploring students' characteristics, learning styles and interests, then adapt the writing activities to better suit their interests and capabilities. The adaptation can be done by (1) personalization; (2) supplements to the activities by adding engaging texts on the same theme which could include written texts, photos and info-graphics; (3) taking advantages of the online resources, which are often more engaging than printed versions; and (4) introducing students to the website writeandimprove.com where they can produce pieces of writing with immediate editing suggestions.

\subsection{Implications for pronunciation practices}

Pronunciation practices are not sufficient, so teachers should (1) design handouts for classroom use; or (2) introduce them to some software like Pronunciation Power for their practice outside the classroom; or (3) design practices on the website quizlet.com, which can help students to learn both pronunciation and vocabulary of topics.

\subsection{Implications for teaching culture content}

As reported, the coursebook is both up-todate and authentic, so some culture elements are contextualized and localized, which embrace culture of other countries rather than Vietnam. It is advisable that teachers pay more attention to culture contents. While teaching, teachers should explain target culture patterns clearly, compare and contrast with Vietnamese culture, and adapt tasks with substitutes of Vietnamese cultural contents.

\section{Conclusion}

In conclusion, the coursebook has proven to be a suitable and good one, which is shown by relevant contents, grammatical structures and activities of listening, speaking, reading and writing. The data also shows that the topics in the book are realistic and rich; and the content is consistently suitable for students' interests, age and background knowledge. Notably, the integrated curriculum is relevant to the training objectives and ICTU teaching-learning context. Therefore, following the lesson progression and the alignment between lessons, students can develop their linguistic knowledge and language skills to achieve expected language proficiency standard. That is why the main criteria to evaluate, general attributes and learning-teaching content, were received positive feedbacks. Despite some weaknesses in pronunciation practices, writing activities, and cultural content, the study indicated that the coursebook should be continued to be used for ICTU students. 


\section{Acknowledgements}

The paper is the product of the basis-level project entitled "Evaluating the effectiveness of the coursebook "Life Elementary" used for students at TNU - University of Information and Communication Technology" coded T2019-07-18 financially supported by ICTU.

\section{REFERENCES}

[1]. J. Mukundan, R. Hajimohammadi and V. Nimehchisalem, "Developing an English Language Textbook Evaluation Checklist: A Focus Group Study," International Journal of Humanities and Social Science, vol. 1, no. 12, pp. 100-106, 2011.

[2]. Thai Nguyen University of Information and Communication Technology, Project on standardization of foreign language and informatics skills for IT staff and students, 2017-2020 (Issued together with Decision No. 1026/QD-DH CNTT\&TT of November 9, 2017), 2017.
[3]. M. T. Tran, T. B. N. Nguyen and T. L. Nguyen, "Blending Quizlet and Edmodo for Designing English Vocabulary Practices: An Experimental Study," TNU Journal of Science and Technology, vol. 186, no. 10, pp. 153158, 2018.

[4]. B. Tomlinson, Materials Development in Language Teaching. Cambridge University Press, Cambridge, 1998.

[5]. T. Dudley-Evans and M. J. St. John, Development in English for Specific Purposes. Cambridge University Press, Cambridge, 1998.

[6]. T. Hutchinson and A. Water, English for Specific Purposes, Cambridge University Press, 1987.

[7]. A. Cunningsworth, Evaluating and Selecting EFL Teaching Materials. Heinemann Educational Books, London, 1984.

[8]. I. McGrath, Materials Evaluation and Design for Language Teaching. Edinburgh University Press, Edinburgh, 2002.

[9]. A. Soori and T. Jamshidi, "Textbook evaluation for the students of speech therapy," Advances in Language and Literary Studies, vol. 4, no. 2, pp. 159-164, 2013. 